\title{
Bioequivalence of Two Oral Contraceptive Drugs Containing Ethinylestradiol and Gestodene in Healthy Female Volunteers
}

\author{
Eduardo Abib Junior ${ }^{1,2 *}$, Luciana Fernandes Duarte $^{2}$, Moisés Luís Pirasol Vanunci ${ }^{2}$, Melissa Lattaro Teixeira ${ }^{3}$
}

${ }^{1}$ Department of Clinical Medicine, Faculty of Medical Sciences, State University of Campinas (UNICAMP), 13083-970, Campinas, SP, Brazil, Tel: (19) 3521-7098

Scentryphar Clinical Research, 13020-420, Campinas, SP, Brazil, Tel: (19) 3232-6350

${ }^{3}$ Sandoz do Brasil, 86183-600, Cambé, Pr, Brazil, Tel: (43) 3174-8000

\begin{abstract}
The bioavailability and bioequivalence of two different film coated tablets containing ethinylestradiol and gestodene were investigated in 36 healthy female volunteers after oral single-dose administration. The study was performed according to a single-center, randomized single-dose, 2-way cross-over design with a wash-out phase of 28 days. Blood samples for pharmacokinetic profiling were taken postdose up to $72 \mathrm{~h}$ (ethinylestradiol) and $96 \mathrm{~h}$ (gestodene). Ethinylestradiol and gestodene plasma concentrations were determined with a validated LC-MS/MS method. Bioequivalence between the products was determined by calculating $90 \%$ confidence intervals $(90 \%$ I.C) for the ratio of $A \cup C_{0}$ and $C_{\text {max }}$ values for the test and reference products, using logarithmic transformed data. The $90 \%$ confidence intervals of ethinylestradiol were $98.49 \%-109.19 \%$, and $100.62 \%-111.69 \%$, respectively. The $90 \%$ confidence intervals of gestodene were $94.07 \%-105.91 \%$, and $110.19 \%-124.73 \%$, respectively. Since the $90 \%$ confidence intervals for $\mathrm{C}_{\max }$ and $\mathrm{AUC}_{0-\mathrm{t}}$ were within the $80-125 \%$ interval proposed by Food and Drug Administration, it was concluded that the two ethinylestradiol and gestodene formulations are bioequivalent in their rate and extent of absorption.
\end{abstract}

Keywords: Therapeutic Equivalency; Biological availability; Pharmacokinetics; Chromatography; Bioequivalence

\section{Introduction}

Combination contraceptives are most effective means for contraception excluding sterilization. Contraceptives are hormonal agents; combination oral contraceptives contain both an estrogen (ethinylestradiol or mestranol) and a progestogen (many different progestogens are utilized throughout the world). Endogenous estrogens are largely responsible for the development and maintenance of the female reproductive system and secondary sexual characteristics. Estrogens act through binding to nuclear receptors in estrogenresponsive tissues. These will vary in proportion from tissue to tissue. Circulating estrogens modulate the pituitary secretion of the gonadotropins, luteinizing hormone ( $\mathrm{LH})$, and follicle-stimulating hormone (FSH), through a negative feedback mechanism [1-4]. Modern progestogens such as gestodene have been developed in order to provide women with an oral contraceptive agent with more selective progestational activity that improves cycle control, minimizes metabolic changes and adverse events, and effectively prevents pregnancy [1]. Of these agents, gestodene has been shown to be a particularly effective inhibitor of ovarian activity with a pronounced progestational effect on the endometrium in both preclinical and clinical trials [2].

The primary estrogen used in oral contraceptives is ethinylestradiol. 17-Ethinylestradiol, a synthetic estrogen developed in 1938, is an essential constituent of oral contraceptives, which have been widely prescribed since the 1970s [5]. In general, ethinylestradiol is used in combination to prevent pregnancy in women [6,7]. Ethinylestradiol is rapidly and completely absorbed from the gastrointestinal tract [810]. Ethinylestradiol undergoes extensive first-pass metabolism, and its absolute bioavailability is approximately $40 \%-60 \%$. After single oral administration, peak plasma concentrations of ethinylestradiol are reached within 1-2 hours [11,12]. Following repeated oral administration, the serum concentration of ethinylestradiol is increased by approximately $30 \%-60 \%$, reaching a steady-state level during the second half of each treatment cycle [13]. Ethinylestradiol is primarily metabolized by aromatic hydroxylation, but a wide variety of hydroxylated and methylated metabolites are formed, and these are present as free metabolites and as conjugates with glucoronide and sulfate $[10,14,15]$. Serum ethinylestradiol levels decrease in two phases, and its terminal half-life is approximately 16-21 hours during repeated administration $[12,16]$. Active metabolites of ethinylestradiol are excreted to a greater extent in the faeces than in the urine $[8,9]$.

Gestodene has been combined with low doses of ethinylestradiol to provide low-dose combination oral contraceptive (COC) preparations. While low-dose COCs are the most widely prescribed form of oral contraceptive today and have a low failure rate in terms of unintended pregnancies, approximately $50 \%$ of all women who begin taking oral contraceptives discontinue their use within one year [3]. Of the factors attributed to noncompliance and/or discontinuation of a COC preparation, poor cycle control (ie, spotting, breakthrough bleeding, and amenorrhea) is the most frequently cited reason for discontinuation. Headache, weight gain, and breast tenderness are also frequently cited reasons for COC discontinuation [3]. As demonstrated by the data presented in the Clinical Experience, Clinical Safety and Tolerability the gestodene-containing COC preparation, effectively combines ethinylestradiol and gestodene to provide high contraceptive efficacy with good cycle control, minimal changes in metabolic functions, and a low incidence of common COC side effects[17-21]. Gestodene is rapidly and completely absorbed from the GI tract with peak plasma concentration occurring in about 1-2 hours. Gestodene is extensively metabolised in the liver but does not undergo significant first pass metabolism. The terminal elimination half-life ranges from 13-18 hours following oral administration. This half-life is increased $(20 \mathrm{hr})$ after repeated administration. Gestodene is $98 \%$ plasma protein bound. Metabolites of gestodene are excreted in urine (50\%) and faeces $(33 \%)[8,11,22,23]$.

*Corresponding author: Eduardo Abib Junior, Scentryphar Clinical Research 885, Barão de Itapura ave, Campinas, SP - Brazil. 13020-420, Tel: (19) 3232-6350, Fax: (19) 3231-6715; E-mail: eabib@scentryphar.com

Received November 18, 2010; Accepted January 04, 2011; Published January 04, 2011

Citation: Junior EA, Duarte LF, Pirasol Vanunci ML, Teixeira ML (2010) Bioequivalence of Two Oral Contraceptive Drugs Containing Ethinylestradiol and Gestodene in Healthy Female Volunteers. J Bioequiv Availab 2: 125-130. doi:10.4172/jbb.1000044

Copyright: ( $) 2010$ Junior EA, et al. This is an open-access article distributed under the terms of the Creative Commons Attribution License, which permits unrestricted use, distribution, and reproduction in any medium, provided the original author and source are credited. 
The aim of this study was to compare in healthy volunteers, the pharmacokinetics profiles and evaluate the bioequivalence of one test formulation contain $0.015 \mathrm{mg}$ ethinylestradiol and $0.060 \mathrm{mg}$ gestodene (Amiga), elaborated by Sandoz, Brazil (test formulation). The test formulation was compared to one commercial formulation contain $0.015 \mathrm{mg}$ ethinylestradiol and $0.060 \mathrm{mg}$ gestodene (Minesse ${ }^{\circ}$ ) by Wyeth Whitehall, Brazil (reference formulation).

\section{Methods}

\section{Study subjects}

Thirty six healthy female volunteers were selected for the study. All volunteers were healthy as assessed by physical examination, gynecological examination, electrocardiogram (ECG), oncotic cytology (Papanicolaou) and the following laboratory tests: blood glucose, urea, creatinine, uric acid, alanine and aspartate aminotransferases (ALT and AST), gamma-gluthamil transferase $(\gamma-\mathrm{GT})$, alkaline phosphatase, total billirubin, albumin and total protein, trygliceride, total cholesterol, hemoglobin, hematocrit, total and differential white cell counts, red blood cell counts, platelet counts and routine urinalysis. All subjects were negative for human immunodeficiency virus, and B (except for serological scar) and $\mathrm{C}$ hepatitis virus.

\section{Study procedures}

All subjects gave written informed consent and the study was conducted in accordance with the revised Declaration of Helsinki, the rules of Good Clinical Practice (ICH-GCP) and the Resolutions No. 196/96 and 251/97 of National Health Council - Health Ministry, Brazil. The clinical protocol was approved by the Research Ethics Committee of University of Campinas/Unicamp (São Paulo, Brazil) and the National Sanitary Surveillance Agency (ANVISA).

The study was a single dose, two-way randomized crossover design with a 28 days washout period between the doses.

During each period, the volunteers were hospitalized at 7:00 p.m. They had the usual evening meal until 9:00 p.m., and an overnight fast (minimum of 10 hours).

The subjects were randomly assigned to one of the two treatment sequences. Each treatment consisted of a single dose of one tablet, corresponding to a dose of $0.015 \mathrm{mg}$ ethinylestradiol and $0.060 \mathrm{mg}$ gestodene. Both treatments were administered orally. Subjects drank $200 \mathrm{~mL}$ of water at room temperature with each application. The oral cavity was inspected after administration.

All volunteers were then fasted for $4 \mathrm{~h}$ following drug administration; afterwards a standard lunch was consumed. Standard snack and evening meal were provided 7-8 and 10-12 h after dosing, respectively. No other food was permitted during the confinement period. Liquid consumption was allowed ad libitum $2 \mathrm{~h}$ after drug administration. However, xanthine-containing drinks including tea, coffee, and cola were avoided.

Blood samples $(06 \mathrm{~mL})$ were collected by indwelling catheter into EDTA containing tubes before dosing and 15, 30, $45 \mathrm{~min}$ and also 1, $1.25,1.5,1.75,2,2.50,3,4,6,8,12,16,24,36,48,72,96 \mathrm{~h}$ post-dosing for ethinylestradiol and gestodene. The blood samples were centrifuged at $3.000 \mathrm{rpm}$ for $10 \mathrm{~min}$. at $4^{\circ} \mathrm{C}$ and the plasma decanted and storage at $-20^{\circ} \mathrm{C}$ until assay for their ethinylestradiol and gestodene content. All samples from a single volunteer were analyzed on the same day in order to avoid interassay variation.
Arterial pressure (measured non-invasively with a sphygmomanometer), heart rate and temperature were recorded just before and after drug administration at each full-hour sample collection.

\section{Formulations}

The test formulation employed was ethinylestradiol and gestodene (lot number 46475) and the reference formulation was Minesse (lot number 50796). Ethinylestradiol and gestodene (Amiga) test formulation, manufactured by Sandoz (Paraná, Brazil) and Minesse reference formulation, manufactured by Wyeth Whitehall (São Paulo, Brazil).

\section{Chemicals and reagents}

Ethinylestradiol was purchased from United States Pharmacopea (lot number QOC162, Rockville, Maryland, USA). 17a-Ethinylestradiol-d4 was obtained from CDN Isotopes (lot number H352P54, Pointe-Claire, Quebec, Canada). Gestodene was purchased from SynFine Research (lot number H787, Richmond Hill, Ontario, Canada). Norethindrone was obtained from United States Pharmacopea (lot number L0F237, Rockville, Maryland, USA). Acetonitrile, methanol, chlorobutane and hexane (HPLC grade). Ultrapure water was obtained from a Milli-Q system. Blank human blood was collected from healthy, drug-free volunteers. Plasma was obtained by centrifugation of blood treated with the anticoagulant EDTA (BD Vacutainer ${ }^{\oplus}, \mathrm{BD}$, Franklin Lakes, NJ, USA). Blank pooled plasma was prepared and stored at $-20^{\circ} \mathrm{C}$ until needed.

\section{Analytical method}

Ethinylestradiol and its internal standard ethinylestradiol-d4 were extracted from a $0.600 \mathrm{~mL}$ aliquot of human EDTA plasma by liquidliquid extraction and derivatization procedure. The plasma samples are thawed at room temperature, mixed and then centrifuged. To the plasma samples is added the internal standard working solution and buffer. The samples are vortexed adequately. 1-chlorobutane is added to the samples. The samples are shaken adequately and centrifuged. The organic phase is transferred into borosilicate tubes and evaporated to dryness. The derivatization buffer solution and the derivatization reagent are added to each sample. The samples are vortexed adequately and incubated for the derivatization step. To the samples is added the hexanes and the samples are vortexed adequately and centrifuged. The organic phase is transferred into borosilicate tubes and evaporated to dryness. The samples are reconstituted with the reconstitution solution prepared with methanol and Milli-Q type water and then vortexed.

Gestodene and its internal standard norethindrone were extracted from a $200 \mu \mathrm{L}$ aliquot o human EDTA plasma by liquid-liquid back extraction, derivatization and solid phase extraction. The plasma samples are thawed at room temperature, mixed and then centrifuged. To the plasma samples is added the internal standard working solution and the buffer solution. The samples are mixed adequately. To the samples are added the extraction solvent. The samples are shaken adequately and centrifuge. The organic phase is transferred into borosilicate tubes and evaporated to the dryness. The catalysing solution, the derivatization reagent (5-dimetilamino-1-naphthalenesulfonyl cloreto Dns-Cl) and methanol are added to each sample. The samples are mixed adequately and incubation for the derivatization step. The samples are evaporated to the dryness, the washing solution is added and the samples are shaken adequately. The samples are transferred on an activated Oasis HLB $30 \mathrm{mg}, 1 \mathrm{cc}$ solid phase extraction cartridges. The cartridges are washed with washing solution and the compound was eluted with methanol, and evaporated to dryness. The samples are reconstituted with the reconstitution solution and then mixed. Ethinylestradiol and 
gestodene plasma concentrations were determined with a LC-MS/MS method [24-30].

\section{Apparatus}

The ethinylestradiol samples were injected into a Zorbax SB-C18, $4.6 \times 50 \mathrm{~mm}, 3.5 \mu \mathrm{m}$ column and a Applied Biosystems Sciex API 5000 tandem mass spectrometer. The mobile a phase was methanol-water $(78: 22, \mathrm{v} / \mathrm{v})$, acetic acid glacial $0.2 \%(\mathrm{v} / \mathrm{v})$, and the mobile phase B was a mixture of acetonitrile $100 \%$ and acetic acid glacial $0.2 \%(\mathrm{v} / \mathrm{v})$. The chromatographic condition was a gradient mode performed at $35^{\circ} \mathrm{C}$ and at a flow rate of $1 \mathrm{~mL} / \mathrm{min}$. for pump $\mathrm{n}^{\circ} 1$ and $0.5 \mathrm{~mL} / \mathrm{min}$. for pump $\mathrm{n}^{\circ}$. 2 . The mass spectrometer was operated with + ESI and MRM using the optimized transitions $530.3 \rightarrow 171.1$ for the ethinylestradiol derivate and $534.4 \rightarrow 171.1$ for the ethinylestradiol-d4 derivative.

The gestodene samples were injected into a Synergi Polar RP 80A, $4 \mu, 50 \times 4.6 \mathrm{~mm} /$ Synergi MAX RP $80 \mathrm{~A}, 4 \mu, 50$ x 4.6mm columns and a Applied Biosystems Sciex API 4000 tandem mass spectrometer. The chromatographic separation was isocratically performed at room temperature at a flow rate of $1 \mathrm{~mL} / \mathrm{min}$. The mobile phase A was a mixture of Milli-Q type water / acetonitrile / methanol (25/50/25, v/v), ammonium acetate $15 \mathrm{mM}$, and the mobile phase $\mathrm{B}$ was acetonitrile $100 \%$. The mass spectrometer was operated with + ESI and MRM using the optimized transitions $444.3 \rightarrow 365.3$ for the gestodene derivate and $432.4 \rightarrow 353.3$ for the norethindrone derivative.

\section{Calibration}

The calibration range of ethinylestradiol was $1.00-100.00 \mathrm{pg} / \mathrm{mL}$. Calibration standards with 8 concentrations $(1.00,2.00,4.00,10.00$, $20.00,40.00,80.00,100.00 \mathrm{pg} / \mathrm{mL}$ ) and quality control standards with 4 concentrations $(3.00,7.50,35.00,75.00 \mathrm{pg} / \mathrm{mL})$ were prepared in human EDTA plasma. The calibration range of gestodene was 50.64$6330.00 \mathrm{pg} / \mathrm{mL}$. Calibration standards with 8 concentrations $(50.64$, $101.28,253.20,633.00,1266.00,2532.00,5064.00,6330.00 \mathrm{pg} / \mathrm{mL})$ and quality control standards with 4 concentrations (126.80, 507.20, $1902.00,4438.00 \mathrm{pg} / \mathrm{mL}$ ) were prepared in human EDTA plasma.

\section{Method validation}

Quantitation was based on determination of relationship between ethinylestradiol and gestodene peaks areas and I.S. peaks areas. Selectivity was evaluated by extracting plasma samples of plasma from different volunteers, including a lipemic and hemolysed plasma. Recoveries of ethinylestradiol and gestodene at the three QC concentrations and I.S. were determined by comparing peak areas of spiked plasma samples with the peak area in solutions prepared with the same nominal concentration. For precision (as relative standard deviation, R.S.D.) and accuracy (as relative error,R.E.) studies, samples were prepared at four QC and were analysed in the same day (intraday precision and accuracy), and analysed in 3 consecutive days (inter-day precision and accuracy).

The calibration curves were processed and the correlation coefficient was equal to or greater than 0.9921 (ethinylestradiol) and 0.9950 (gestodene). In ethinylestradiol and gestodene the precision of back-calculated calibration standard concentrations ranged from $2.40-7.00 \%$ and $2.96-5.45 \%$, respectively. In ethinylestradiol the intraday accuracy and precision of the quality control samples ranged from 98.24-99.35\% and $2.99-4.83 \%$. In gestodene the intra-day accuracy and precision of the quality control samples ranged from $96.35-99.51 \%$ and $5.05-5.89 \%$. Similar accuracy and precision values were observed during the study sample analysis.

The stability was also evaluated in plasma samples kept at $-20^{\circ} \mathrm{C}$ for
221 days (ethinylestradiol) and 181 days (gestodene). Stability samples were processed with a freshly prepared calibration curve and analyzed a single run. Mean concentrations of the stability samples were compared to the mean concentrations comparison samples. All samples described above were compared to freshly prepared ethinylestradiol and gestodene samples at the same concentration level. All sample analysis was carried out in a GLP-compliant manner and in accordance with the current Brazilian Regulatory Agency (ANVISA) requirements and the US Food and Drug Administration Bioanalytical method validation guidance.

\section{Pharmacokinetics and statistical analysis}

The first-order terminal elimination rate constant (Ke) was estimated by linear regression from the points describing the elimination phase on a log-linear plot, using the software SAS ${ }^{\circledast}$ Institute (Version 9.1.3). Elimination half-life $\left(\mathrm{T}_{1 / 2}\right)$ was derived from this rate constant $\left(\mathrm{T}_{1 / 2}=\ln (2) / \mathrm{Ke}\right)$. The maximum observed plasma concentration $\left(\mathrm{C}_{\max }\right)$ and the time taken to achieve this concentration $\left(\mathrm{T}_{\max }\right)$ were obtained directly from the curves. The areas under the ethinylestradiol $\left(\mathrm{AUC}_{0-72 \mathrm{~h}}\right)$ and gestodene $\left(\mathrm{AUC}_{0-96 \mathrm{~h}}\right)$ plasma concentration versus time curves from were calculated by applying the linear trapezoidal rule. In ethinylestradiol extrapolation of these areas to infinity $\left(\mathrm{AUC}_{0 \text {-inf }}\right)$ was done by adding the value $\mathrm{C} 72 / \mathrm{Ke}$ to the calculated $\mathrm{AUC}_{0-72 \mathrm{~h}}$ (where $\mathrm{C} 72=$ plasma concentration calculated from the log-linear regression equation obtained for the estimation of Ke 72 hours after dose). In gestodene extrapolation of these areas to infinity $\left(\mathrm{AUC}_{0 \text {-inf }}\right)$ was done by adding the value $\mathrm{C} 96 / \mathrm{Ke}$ to the calculated $\mathrm{AUC}_{0-96 \mathrm{~h}}$ (where $\mathrm{C} 96=$ plasma concentration calculated from the log-linear regression equation obtained for the estimation of Ke 96 hours after dose).

The bioequivalence between both formulations was assessed by calculating individual $\mathrm{C}_{\max }, \mathrm{AUC}_{0-\mathrm{t}}, \mathrm{AUC}_{0 \text {-inf }}$ and $\mathrm{C}_{\max } / \mathrm{AUC}_{0-\mathrm{t}}$ ratios (test/reference) together with their mean and $90 \%$ confidence intervals (CI) after log transformation of the data. The inclusion of the $90 \% \mathrm{CI}$ for the ratio in the $80 \%$ to $125 \%$ range was analyzed by nonparametric (SAS ${ }^{\circledast}$ Institute Version 9.1.3) and parametric (ANOVA) methods.

\begin{tabular}{|l|c|}
\hline \multicolumn{1}{|c|}{ Category } & Volunteers \\
\hline $\mathrm{n}$ & 36 \\
\hline Age $($ Years $)$ & $34.17 \pm 5.94$ \\
\hline Height $(\mathrm{cm})$ & $1.59 \pm 0.06$ \\
\hline Weight $(\mathrm{Kg})$ & $62.08 \pm 7.83$ \\
\hline BMI $\left(\mathrm{Kg} / \mathrm{m}^{2}\right)$ & $24.50 \pm 2.57$ \\
\hline
\end{tabular}

Table 1: Summary of demographic characteristics for the safety population for study (mean $\pm S D)$.

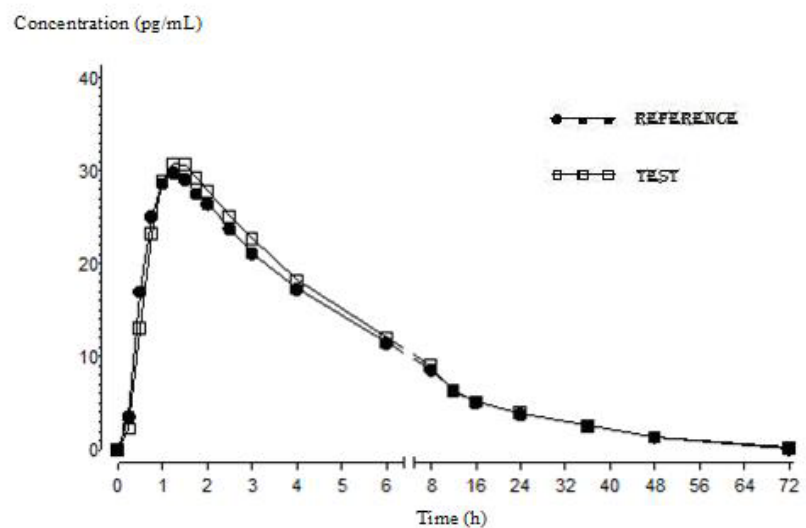

Figure 1: Mean plasma concentration-time profile of ethinylestradiol over the first $72 \mathrm{~h}$ after oral administration of the test and reference formulation. 
Citation: Junior EA, Duarte LF, Pirasol Vanunci ML, Teixeira ML (2010) Bioequivalence of Two Oral Contraceptive Drugs Containing Ethinylestradiol and Gestodene in Healthy Female Volunteers. J Bioequiv Availab 2: 125-130. doi:10.4172/jbb.1000044

\section{Results}

\section{Demography and safety}

Thirty three of the 36 enrolled subjects completed the study. Two subjects dropped in phase two for personal reasons. One subject dropped out before confinement in phase two for clinical laboratory investigations abnormal. Hence 33 completed cases for both treatments were available for analysis of ethinylestradiol and gestodene plasma concentrations. The demographic characteristics of the study subjects are presented in Table 1, including age, height, weight and BMI. Ethinylestradiol and gestodene were well tolerated at the administered dose. No severe adverse effects occurred.

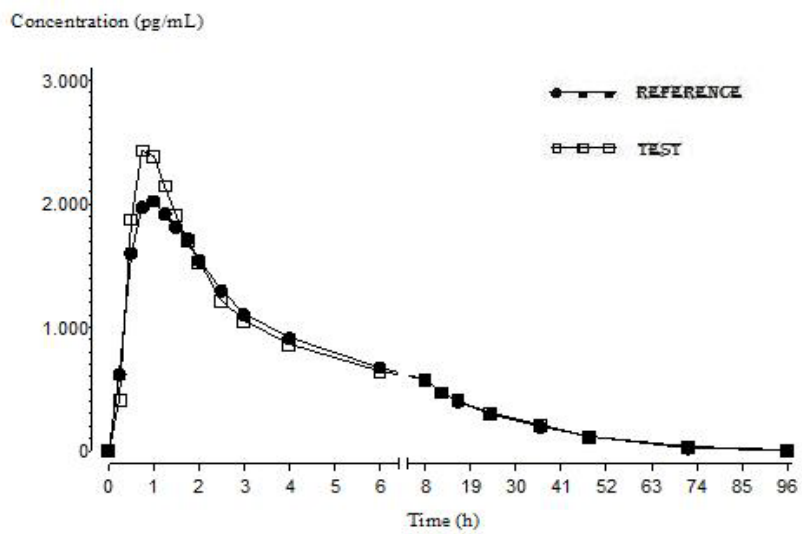

Figure 2: Mean plasma concentration-time profile of gestodene over the first 96 $\mathrm{h}$ after oral administration of the test and ference formulation.

\section{Pharmacokinetic and statistical analysis}

The mean $( \pm \mathrm{SD})$ plasma concentration-time profiles are presented in (Figure 1) (ethinylestradiol) and (Figure 2) (gestodene) and the pharmacokinetic parameters of both substances are summarized in Table 2 and Table 3 .

The mean of $\mathrm{C}_{\max }$ of ethinylestradiol was $31.75 \mathrm{pg} / \mathrm{mL}$ in reference product and $33.71 \mathrm{pg} / \mathrm{mL}$ in test product. Both occurred $1.25 \mathrm{~h}$ after application. $\mathrm{C}_{\max }$ of gestodene was on average $2290.04 \mathrm{pg} / \mathrm{mL}$ in reference product and $2663.22 \mathrm{pg} / \mathrm{mL}$ in test product and occurred $1 \mathrm{~h}$ after administration (reference) and $0.75 \mathrm{~h}$ (test). For ethinylestradiol, the geometric means of $\mathrm{AUC}_{0-\infty}$ as a measure of extent of absorption amount to 340.09 pg.h/mL (reference) and 340.17 pg.h $/ \mathrm{mL}$ (test) The geometric means of $\mathrm{AUC}_{0-\infty}$ of gestodene are $23247.71 \mathrm{pg} . \mathrm{h} / \mathrm{mL}$ (reference) and $23616.28 \mathrm{pg} . \mathrm{h} / \mathrm{mL}$ (test). The values of $\mathrm{AUC}_{0 . \mathrm{t}}$ for ethinylestradiol are 286.81 pg.h $/ \mathrm{mL}$ (reference) and $297.91 \mathrm{pg} . \mathrm{h} / \mathrm{mL}$ (test). In the gestodene evaluation the amounts of $\mathrm{AUC}_{0-\mathrm{t}}$ are 20624.24 pg.h/mL (reference) and 21261.70 pg.h $/ \mathrm{mL}$ (test). No significant differences with respect to drug absorption were found. Elimination half-lives and elimination rate constancy were well comparable between the different preparations.

The resulting $90 \%$ confidence intervals of the parameter ratios for for $\mathrm{AUC}_{0-\infty}, \mathrm{AUC}_{0-\mathrm{t}}$ and $\mathrm{C}_{\max }$ as well as for differences in $\mathrm{t}_{\max }$ are summarized in Table 4 .

\section{Discussion}

Preventing unwanted pregnancy has been an important issue for women and their families all over the world for many hundreds of years. With the development of oral hormonal contraceptives, the so-called

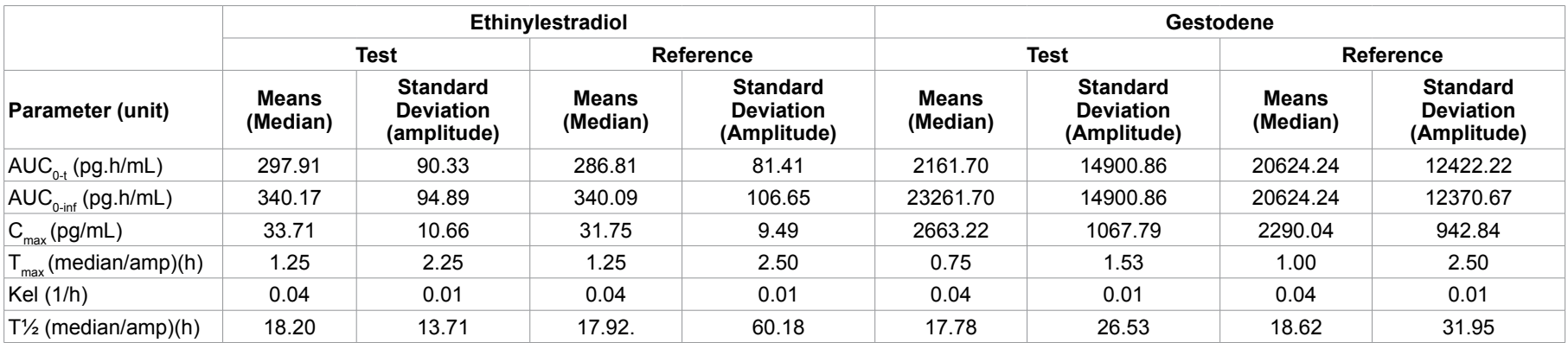

Table 2: Mean pharmacokinetic parameters of ethinylestradiol and gestodene of test and reference formulation.

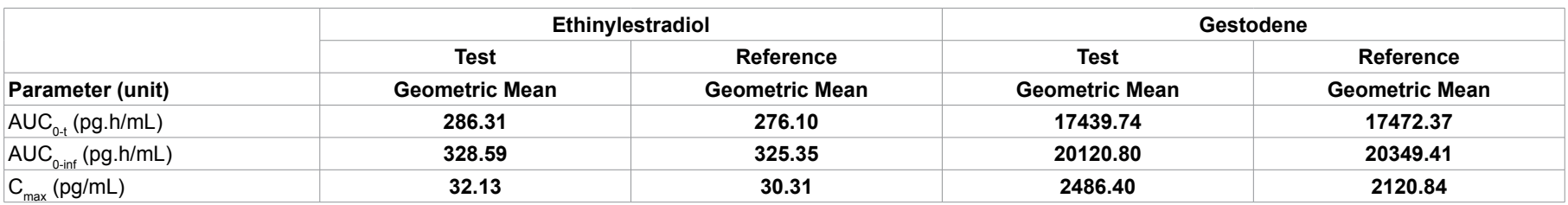

Table 3: Geometric mean pharmacokinetic parameters of ethinylestradiol and gestodene of test and reference formulation.

\begin{tabular}{|c|c|c|c|c|c|c|c|c|c|c|}
\hline \multirow[b]{3}{*}{ Parameter (unit) } & \multicolumn{5}{|c|}{ Ethinylestradiol } & \multicolumn{5}{|c|}{ Gestodene } \\
\hline & \multicolumn{3}{|c|}{ Test } & \multicolumn{2}{|c|}{ Reference } & \multicolumn{2}{|c|}{ Test } & \multicolumn{3}{|c|}{ Reference } \\
\hline & $\begin{array}{c}\text { Ratio T/R } \\
(\%)\end{array}$ & $\begin{array}{c}\text { Lower } \\
\text { Limit } \\
(\%)\end{array}$ & $\begin{array}{c}\text { Upper Limit } \\
(\%)\end{array}$ & Power (\%) & $\begin{array}{l}\text { Coefficient of } \\
\text { Variation (\%) }\end{array}$ & $\begin{array}{c}\text { Ratio T/R } \\
\text { (\%) }\end{array}$ & $\begin{array}{l}\text { Lower } \\
\text { Limit (\%) }\end{array}$ & $\begin{array}{c}\text { Upper } \\
\text { Limit (\%) }\end{array}$ & Power (\%) & $\begin{array}{l}\text { Coefficient of } \\
\text { Variation (\%) }\end{array}$ \\
\hline $\mathrm{AUC}_{0-\mathrm{t}}$ & 103.70 & 98.49 & 109.19 & 99.99 & 10.40 & 99.81 & 94.07 & 105.91 & 99.99 & 14.27 \\
\hline$A \cup C_{0 \text {-inf }}$ & 100.99 & 95.99 & 106.26 & 99.99 & 12.23 & 98.88 & 93.52 & 104.54 & 99.99 & 13.40 \\
\hline $\mathrm{C}_{\max }$ & 106.01 & 100.62 & 111.69 & 99.98 & 12.55 & 117.24 & 110.19 & 124.73 & 52.82 & 14.92 \\
\hline$T_{\max }(\operatorname{dif})(\mathrm{h})$ & 0.00 & 0.00 & 0.25 & - & - & -0.25 & -0.50 & 0.00 & - & - \\
\hline
\end{tabular}

Table 4: Ratios means and the $90 \%$ geometric confidence interval of test and reference formulation. 
"Pill", in the early 1960s, women finally had access to a revolutionary method of contraception $[31,32]$.

Combined oral contraceptives are effective in effects on menses (improved menstrual cycle regularity, decreased incidence of dysmenorrhea, decreased blood loss and decreased incidence of irondeficiency anemia), effects related to inhibition of ovulation (decreased incidence of functional ovarian cysts and decreased incidence of ectopic pregnancies), decreased severity of acne and decreased incidence of acute pelvic inflammatory disease, endometrial cancer, ovarian cancer, fibroadenomas and fibrocystic disease of the breast [33-41]

When a new oral contraceptives formulation is developed, it is crucial to ensure optimum hormone exposure during concomitant therapy with other substances, while also guaranteeing the lowest dose to prevent pregnancy and avoid side effects. To enable testing that can deal with these concerns, a highly sensitive analytical method with a low limit of quantification (LLOQ) is required to accurately measure oral contraceptives concentrations in human plasma samples.

Immunoassay methods have been the most sensitive analytical procedures available for the determination of estrogens in biological samples for many years [42-44]. These methods are sensitive, but are time consuming and prone to cross reactivity by steroids and their metabolites. Gas chromatographic coupled to mass spectrometric (GC-MS) methods typically employ some type of extraction, and one or multiple steps of derivatization [45-47]. Recently, liquid chromatography with tandem mass spectrometric (LC-MS/MS) detection has been applied for the quantitative analysis of estrogens in environmental and biological samples. LC-MS/MS is superior to immunoassay methods or GC/MS in terms of simplicity, sensitivity, selectivity and analytical throughput [24-30]

Only limited number of information concerning gestodene mass spectrometric determination have been published [24]. The LC-MS/ MS method described here is specific due to the inherent selectivity of tandem mass spectrometry is in accordance with both Food and Drug Administration (FDA) and the National Sanitary Surveillance Agency (ANVISA) requirements for pharmacokinetic studies. This method offers the advantage over those previously reported using LC-MS/MS $[24,27,29,48]$ showing a low validated LOQ $1 \mathrm{pg} \mathrm{mL}^{-1}$ (ethinylestradiol) and LOQ $50.64 \mathrm{pg} \mathrm{mL}^{-1}$ (gestodene).

The mean ratio of parameters $\mathrm{C}_{\max }$ and $\mathrm{AUC}_{0-\mathrm{t}}$ and $90 \%$ confidence intervals of correspondents were calculated to determine the bioequivalence. The point estimator and the $90 \%$ confidence intervals for the $\mathrm{AUC}_{0-\mathrm{t}}$ ratio (test/reference: $103.70 \%$ [98.49\% - 109.19\%]) indicate high similarity of both formulations with respect to the extent of ethinylestradiol exposure. A high degree of similarity was also observed for $\mathrm{C}_{\max }$ of ethinylestradiol, as the point estimator and the $90 \%$ confidence interval for the $\mathrm{C}_{\max }$ ratio are $106.01 \%(100.62 \%-111.69 \%)$. Regarding the $\mathrm{AUC}_{0-\mathrm{t}}$ ratio of gestodene, the point estimator is $99.81 \%$ and the $90 \%$ confidence interval $94.07 \%$ - 105.91\%. Furthermore, exchangeability of both formulations is also suggested by the point estimator and $90 \%$ confidence of $\mathrm{C}_{\max }$ of this active agent $(117.24 \%$ [110.19\% - 124.73\%]).

The $\mathrm{AUC}_{0-\mathrm{t}}$ and $\mathrm{AUC}_{0-\infty}$ are both recognized as an uncontaminated measurement of the extent of absorption. The present study showed that $90 \% \mathrm{CI}$ of mean $\mathrm{AUC}_{0-\mathrm{t}}$ and $\mathrm{AUC}_{0-\infty}$ (after log-transformation of individual ratios) were included into the bioequivalence range (80$125 \%)$, consequently, the two formulations of ethinylestradiol and gestodene are equivalent for the extend of absorption.
The statistical comparison of $\mathrm{C}_{\max }, \mathrm{AUC}_{0-\mathrm{t}}$ and $\mathrm{AUC}_{0-\infty}$ clearly indicated no significant difference in the two formulations of ethinylestradiol and gestodene. 90\% confidence intervals for the mean ratio (T/R) of $\mathrm{C}_{\max }, \mathrm{AUC}_{0-\mathrm{t}}$ and $\mathrm{AUC}_{0-\infty}$ were entirely is in accordance with both acceptance range the Food and Drug Administration (FDA) and the National Sanitary Surveillance Agency (ANVISA). Based on the pharmacokinetic and statistical results of this study, we can conclude that ethinylestradiol and gestodene (Sandoz, Brazil) is bioequivalent to Minesse $^{\circledR}$ (Wyeth Whitehall, Brazil), and that then the test product can be considered interchangeable in medical practice.

\section{Acknowledgments}

This research work is financially supported by the Scentryphar Clinical Research, Brazil.

\section{References}

1. Wilde MI, Balfour JA (1995) Gestodene: a review of its pharmacology, efficacy and tolerability in combined contraceptive preparations. Drugs 50: 364-395.

2. Gast MJ (1996) A new generation of oral contraceptive progestins: Guest Introduction. Gynecol Endocrinol 10: 1-3.

3. Aguiar LF, Andrade RP, Bossemeyer RP (1996) Monophasic gestodene and ethinylestradiol in oral contraception: a multicenter open study. Gynecol Endocrinol 10: 21-26.

4. Rossmanith WG, Steffens D, Schramm G (1997) A comparative randomized trial on the impact of two low-dose oral contraceptives on ovarian activity, cervical permeability, and endometrial receptivity. Contraception 56: 23-30.

5. Innhoffen $\mathrm{HH}$ (1938) Neue per os-wirksame weibliche KeimdrüsenhormonDerivate: 17-Äthinylöstradiol und Pregnene-in-on-3-ol-17. Naturwissenschaften 26: 96.

6. Keam SJ, Wagstaff AJ (2003) Ethinylestradiol/drospirenone: a review of its use as an oral contraceptive. Treat Endocrinol 2: 49-70.

7. Sartoretto JN, Ortega-Recio JC, Moraes R, Filho FN (1977) Clinical studies with a low dose estrogen-progestogen combination. Contraception 15: 563570 .

8. Goldzieher JW, Dozier TS, de la Pena A (1980) Plasma levels and pharmacokinetics of ethynyl estrogens in various populations. Contraception 21: 1-16.

9. Speck U, Wendt H, Schulze PE, Jentsch D (1976) Bio-availability and pharmacokinetics of cyproterone acetate-14C and ethinyloestradiol-3H after oral administration as a coated tablet. Contraception 14: 151-163.

10. Cargill DI, Steinetz BG, Gosnell E, Beach VL, Meli A, et al. (1969) Fate of ingested radiolabled ethynylestradiol and its 3-cyclopentyl ether in patients with bile fistulas. J Clin Endocrinol Metab 29: 1051-1061.

11. Orme M, Back DJ, Ward S, Green S (1991) The pharmacokinetics of ethynylestradiol in the presence and absence of gestodene and desogestrel. Contraception 43: 305-316.

12. Humpel M, Nieuweboer B, Wendt H, Speck U (1979) Investigations of pharmacokinetics of ethinyloestradiol to specific consideration of a possible first-pass effect in women. Contraception 19: 421-432.

13. Collins DC (1994) Sex hormone receptor binding, progestin selectivity, and the new oral contraceptives. Am J Obstet Gynecol 170: 1508-1513.

14. Abdel-Aziz MT, Williams KIH (1970) Metabolism of radioactive $17 \alpha$-ethynylestradiol by women. Steroids 15: 695-710.

15. Williams MC, Helton ED, Goldzieher JW (1975) The urinary metabolites of

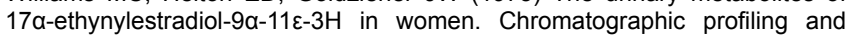
identification of ethynyl and non-ethynyl compounds. Steroids 25: 229-246.

16. Limpongsanurak S, Jenkins N, Fotherby K (1981) Effect of contraceptive steroids on serum levels of sex hormone binding globulin and caeruloplasmin. Curr Med Res Opin 7: 185-191

17. Jung-Hoffmann C, Heidt F, Kuhl H (1988) Effect of two oral contraceptives containing $30 \mu \mathrm{g}$ ethinylestradiol and $75 \mu \mathrm{g}$ gestodene or $150 \mu \mathrm{g}$ desogestre upon various hormonal parameters. Contraception 38: 593-603.

18. Brill K, Then A, Beisiegel U (1996) Investigation of the influence of two lowdose monophasic oral contraceptives containing $20 \mu \mathrm{g}$ ethinylestradiol $/ 75 \mu \mathrm{g}$ 
Citation: Junior EA, Duarte LF, Pirasol Vanunci ML, Teixeira ML (2010) Bioequivalence of Two Oral Contraceptive Drugs Containing Ethinylestradiol and Gestodene in Healthy Female Volunteers. J Bioequiv Availab 2: 125-130. doi:10.4172/jbb.1000044

gestodene and $30 \mu \mathrm{g}$ ethinylestradiol/75 $\mu \mathrm{g}$ gestodene, on lipid metabolism in an open randomized trial. Contraception 54: 291-297.

19. Spellacy WN, Tsibris JC, Hunter-Bonner DL, Smalling S, Chez RA, et al. (1992) Six-month carbohydrate metabolism studies in women using oral contraceptives containing gestodene and ethinyl estradiol. Contraception 45: 533-539.

20. Spellacy WN, Tsibris AM, Tsibris JC, George S, Chez RA, et al. (1994) Carbohydrate metabolism studies after one year of using an oral contraceptive containing gestodene and ethinyl estradiol. Contraception 49: 125-130.

21. Fioretti P, Fruzetti F, Navalesi P (1989) Clinical and metabolic effects of a pil containing $30 \mathrm{mcg}$ of ethinylestradiol plus $75 \mathrm{mcg}$ of gestodene. Contraception 40: 649-663

22. Taüber U, Tack JW, Matthes H (1989) Single dose pharmacokinetics of gestodene in women after intravenous and oral administration. Contraception 40: $461-479$.

23. Dibbelt L, Knuppen R, Kuhnz W, Jutting G (1992) Pharmacokinetics and protein binding of gestodene under treatment with a low-dose combination oral contraceptive for three months. Arzneimittelforschung 42: 1146-1152.

24. Matejícek D, Kuban V (2007) High performance liquid chromatography/ ion-trap mass spectrometry for separation and simultaneous determination of ethynylestradiol, gestodene, levonorgestrel, cyproterone acetate and desogestrel. Anal Chim Acta 588: 304-315.

25. Christiaens B (2004) Fully automated method for the liquid chromatographictandem mass spectrometric determination of cyproterone acetate in human plasma using restricted access material for on-line sample clean-up. Journal of chromatography A 1056: 105-110.

26. Isobe T, Shiraishi H, Yasuda M, Shinoda A, Suzuki H, et al. (2003) Determination of estrogens and their conjugates in water using solid-phase extraction followed by liquid chromatography-tandem mass spectrometry. J Chromatogr A 984: 195-202.

27. Licea-Perez H, Wang S, Bowen CL, Yang E (2007) A semi-automated 96well plate method for the simultaneous determination of oral contraceptives concentrations in human plasma using ultra performance liquid chromatography coupled with tandem mass spectrometry. J Chromatogr B Analyt Technol Biomed Life Sci 852: 69-76.

28. Reddy S,Iden CR, Brownawell BJ (2005) Analysis of steroid estrogen conjugates in municipal waste waters by liquid chromatography-tandem mass spectrometry. Anal Chem 77: 7032-7038.

29. Twaddle NC (2003) Analysis of steroid estrogen conjugates in municipal waste waters by liquid chromatography-tandem mass spectrometry. Journal of chromatography B 793: 309-315.

30. Zuehlke S, Duennbier U, Heberer T (2005) Determination of estrogenic steroids in surface and wastewater applying liquid chromatography-electrospray tandem mass spectrometry. J Sep Sci 28: 52-58.

31. Foster DG, Parvataneni R, de Bocanegra HT, Lewis C, Bradsberry M, et al. (2006) Number of oral contraceptive pill packages dispensed, method continuation, and costs. Obstet Gynecol 108: 1107-1114.

32. Smith JD, Oakley D (2005) Why do women miss oral contraceptive pills? An analysis of women's self-described reasons for missed pills. J Midwifery Womens Health 50: 380-385.

33. Brown S, Vessey M, Stratton I (1988) The influence of method of contraception and cigarette smoking on menstrual patterns. Br J Obstet Gynecol 95: 905-910.
34. Larsson G, Milsom I, Lindstedt G, Rybo G (1992) The influence of a lowdose combined oral contraceptive on menstrual blood loss and iron status. Contraception 46: 327-334

35. Lanes SF, Birmann B, Walker AM, Singer S (1992) Oral contraceptive type and functional ovarian cysts. Am J Obstet Gynecol 166: 956-961.

36. Zhang Z, Weng L, Zhang Z, Jin X, Jing X, et al. (1994) An epidemiologica study on the relationship of ectopic pregnancy and the use of contraceptives in Beijing - the incidence of ectopic pregnancy in the Beijing area. Contraception 50: 253-262.

37. Perdikaris AG, Dimopoulos D, Tzingounis VA (1995) The effect of gestanone and ethinyl estradiol on benign breast disease. Clin Exper Obstet Gynecol 22 28-31.

38. Panser LA, Phipps WR (1991) Type of oral contraceptive in relation to acute, initial episodes of pelvic inflammatory disease. Contraception 43: 91-99.

39. Vessey MP, Painter R (1995) Endometrial and ovarian cancer and ora contraceptives-findings in a large cohort study. Br J Cancer 71: 1340-1342.

40. Ness RB, Grisso JA, Klapper J, Schlesselman JJ, Silberzweig S, et al. (2000) Risk of ovarian cancer in relation to estrogen and progestin dose and use characteristics of oral contraceptives. Am J Epidemiol 152: 233-241.

41. Mango D, Ricci S, Manna P, Miggiano GA, Serra GB, et al. (1996) Clinical and hormonal effects of ethinylestradiol combined with gestodene and desogestrel in young women with acne vulgaris. Contraception 53: 163-170.

42. Back DJ, Breckenridge AM, Crawford FE, Maclver M, Orme ML, et al. (1979) An investigation of the pharmacokinetics of ethynylestradiol in women using radioimmunoassay. Contraception 20: 263-273.

43. Saperstein S, Edgren RA, Lee GJ, Jung D, Fratis A, et al. (1989) Bioequivalence of two oral contraceptive drugs containing norethindrone and ethinyl estradiol. Contraception 40: 581-590.

44. Nieuweboer B, Tack J, Tauber U, Hümpel M, Wendt H (1989) Development and application of a radioimmunoassay of the new progestagen gestodene. Contraception 40: 313-323.

45. Diaz-Cruz MS, Lopez de Alda MJ, Lopez R, Barcelo D (2003) Determination of estrogens and progestogens by mass spectrometric techniques (GC/MS, LC/ MS and LC/MS/MS). J Mass Spectrom 38: 917-923.

46. Giese RW (2003) Measurement of endogenous estrogens: analytical challenges and recent advances. J Chromatogr A 1000: 401-412.

47. Zuo $Y$, Zhang K, Lin Y (2007) Microwave-accelerated derivatization for the simultaneous gas chromatographic-mass spectrometric analysis of natural and synthetic estrogenic steroids. J Chromatogr A 1148: 211-218.

48. Borges NC, Astigarraga RB, Sverdloff CE, Galvinas PR, da Silva WM, et al. (2009) A novel and sensitive method for ethinylestradiol quantification in human plasma by high-performance liquid chromatography coupled to atmospheric pressure photoionization (APPI) tandem mass spectrometry: Application to a comparative pharmacokinetics study. J Chromatogr B Analyt Technol Biomed Life Sci 877: 3601-3609.

49. Audet MC, Moreau M, Koltun WD, Waldbaum AS, Shangold G, et al. (2001) Evaluation of contraceptive efficacy and cycle control of a transdermal contraceptive patch vs an oral contraceptive: a randomized controlled trial. JAMA 285: 2347-2354 